\title{
Chaotic phenomenon in vanadium redox flow battery
}

Keywords: chaotic phenomenon, Energy, ion-exchange, electrochemical, water, chemistry

\section{Short communication}

Vanadium redox flow battery is an efficient energy-storage system because it's long cycle life, flexible design, high efficiency and fast response time. Chaotic phenomenon (electrochemical oscillation) was first observed during the charging process of the anolyte, and the mechanism was investigated. The largest Lyapunov exponent was applied to characterize the chaotic phenomenon.

Vanadium and its compounds are used for manufacturing iron ${ }^{1-3}$ steel non-ferrous metals ${ }^{4}$ catalyst, ${ }^{5,6}$ and petrochemicals because its excellent properties. ${ }^{7,8}$ The vanadium sulfates were applied in vanadium redox flow batteries which proposed by Skyllas-Kazacos et al. ${ }^{9,10}$ in 1985. It was an efficient energy-storage system and had attracted much attention for its long cycle life, flexible design, deepdischarge capability, low pollution emitting and fast response time. ${ }^{11,12}$ The vanadium redox flow batteries were divided into two compartments by an ion-exchange membrane. The positive half cells was V(IV)/ $\mathrm{V}(\mathrm{V})$ redox couples and V(II)/V(III) as the negative half cells. The electricity energy was transferred to chemical energy and stored in the vanadium compounds during the charging process. Studies were most focused on the materials of electrodes, ${ }^{13-15}$ and modification of membrane. ${ }^{16-19}$ Few studies had reported the electrochemical behavior of anolyte during the charging process.

All chemicals were analytical grade. Water was purified with a water purification system (HMC-WS 10, Korea). The anolyte was composed of $\mathrm{VOSO}_{4}(1 \mathrm{M})$ and $\mathrm{H}_{2} \mathrm{SO}_{4}(2 \mathrm{M})$, and the catholyte was $\mathrm{H}_{2} \mathrm{SO}_{4}(2 \mathrm{M})$ with the same volume. The anolyte and catholyte was separated with a Nafion membrane. The anode and cathode used in the experiments was platinum slice $(1.5 \times 2 \mathrm{~cm})$ in which no other unexpected side reaction occurred. They were subjected to ultrasonic cleaning in de-ionized water for $30 \mathrm{~min}$ to remove residues before testing. Electrochemical tests were carried out on CHI660D electrochemical workstation. The signal of the potential was amplified, and the times series were recorded and transferred to a personal computer. The macro-instability frequency, oscillation period, of the potential-time series were obtained using Matlab.

Electrochemical oscillation was observed during the charging process, while the electrochemical tests were carried out on CHI660D electrochemical workstation with the anolyte of $1 \mathrm{M} \mathrm{VOSO}_{4}+2 \mathrm{M}$ $\mathrm{H}_{2} \mathrm{SO}_{4}$, and the catholyte of $2 \mathrm{M} \mathrm{H}_{2} \mathrm{SO}_{4}$ at room temperature, the potential-time series was showed in Figure 1. As indicated in Figure 1 the potential was increased quickly and then electrochemical oscillation emerged. After then, the period of the electrochemical oscillation slowly decreased and then stabilized as showed in Figure 2.

The power consumption was investigated to reveal the influence of electrochemical oscillation on the charging efficiency. An extra power consume was a result of the electrochemical oscillation.
Volume 2 Issue 2 - 2017

\author{
Hao Peng, ${ }^{1,2,3}$ Zuohua Liu, ${ }^{1,2,3}$ Changyuan \\ Tao ${ }^{1,2}$ \\ 'Chongqing Key Laboratory for Clean Energy and Resource \\ Utilization, China \\ ${ }^{2}$ College of Chemistry and Chemical Engineering, Chongqing \\ University, China \\ ${ }^{3}$ College of Chemistry and Chemical Engineering, Yangtze \\ Normal University, China
} Clean Energy and Resource Utilization, College of Chemistry and Chemical Engineering, College of Chemistry and Chemical Engineering, Chongqing University, China, College of Chemistry and Chemical Engineering, Yangtze Normal University, China, Email cqupenghao@।26.com

Changyuan Tao, Chongqing Key Laboratory for Clean Energy and Resource Utilization, College of Chemistry and Chemical Engineering, Chongqing University, China, Email taocy@cqu.edu.cn

Received: February 13, 2017| Published: March 03, 2017

The relative power-consume $(\mathrm{PRC})$ was calculated as $\mathrm{PRC}=$ the average power consumption on anode / (Va·Ia), where Va was the potential, Ia was the charging potential. The results were shown in Figure 3. The influence of electrochemical oscillation on the charging efficiency will be enlarge in long-term charging, and much extra power will be consumed. This part of power consumption should exist in practical charging process, even though it is often ignored. It is beneficial for improving the charge efficiency and energy-saving if the electrochemical oscillation could be regulated.

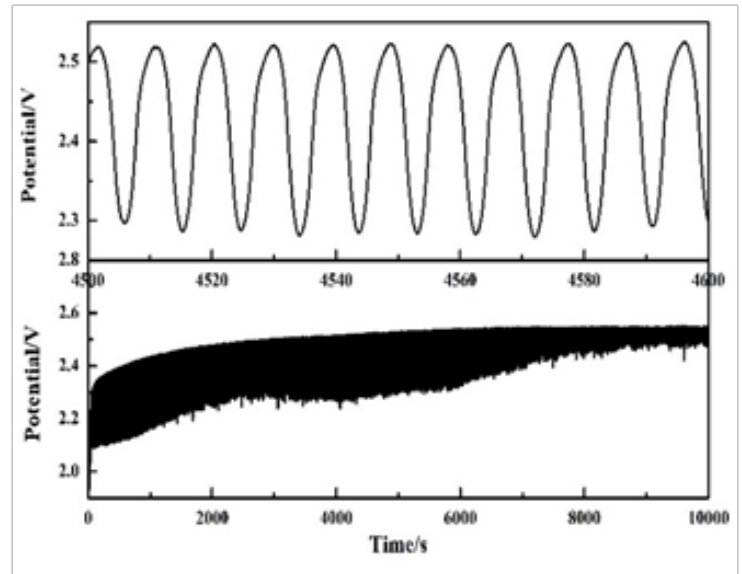

Figure I The Potential-time curve (anolyte: I $\mathrm{M} \mathrm{VOSO}_{4}+2 \mathrm{M} \mathrm{H}_{2} \mathrm{SO}_{4}$; catholyte: $2 \mathrm{M} \mathrm{H}_{2} \mathrm{SO}_{4}$ ).

The mechanism of the electrochemical oscillation was investigated. During the charging process, the main chemical reactions in the system were described in Equation (1) and (2) 


$$
\begin{aligned}
& \text { Anode: } \mathrm{VO}^{2+}+\mathrm{H}_{2} \mathrm{O}-\mathrm{e} \rightarrow \mathrm{VO}_{2}^{+}+2 \mathrm{H}^{+} \\
& \text {Cathode: } 2 \mathrm{H}^{+}+2 \mathrm{e} \rightarrow \mathrm{H}_{2}
\end{aligned}
$$

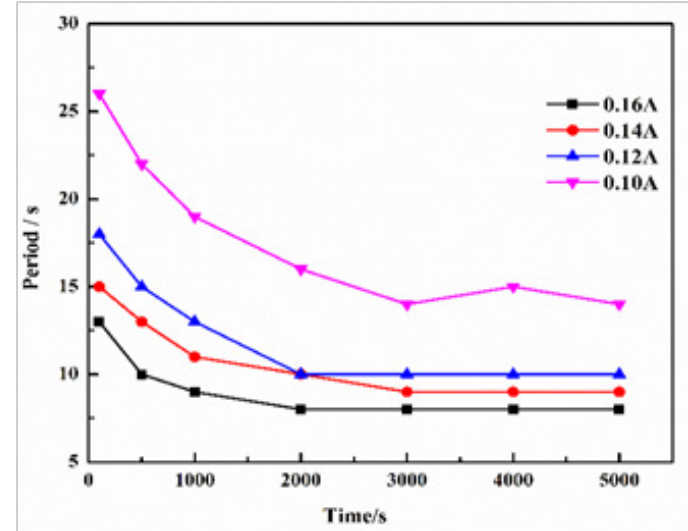

Figure 2 The dependence of oscillation period on the time in different charging current (anolyte: I $\mathrm{MVOSO}_{4}+2 \mathrm{M} \mathrm{H}_{2} \mathrm{SO}_{4}$; catholyte: $2 \mathrm{M} \mathrm{H}_{2} \mathrm{SO}_{4}$ ).

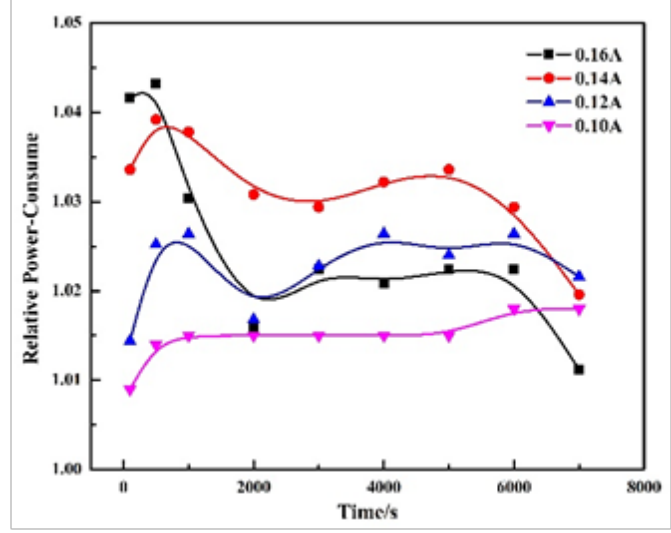

Figure 3 The dependence of relative power-consume on the time in different charging current (anolyte: I $\mathrm{MVOSO}_{4}+2 \mathrm{M} \mathrm{H}_{2} \mathrm{SO}_{4}$; catholyte: $2 \mathrm{M} \mathrm{H}_{2} \mathrm{SO}_{4}$ ).

The $\mathrm{VO}^{2+}$ in the anolyte was oxidized to $\mathrm{VO}_{2}^{+}$on the surface of the anode. As $\mathrm{V}(\mathrm{V})$ had low solubility in high acidic solution ${ }^{20-22} \mathrm{VO}_{2}{ }^{+}$ would hydrolysis and formed $\mathrm{V}_{2} \mathrm{O}_{5}$ according to Equation (3). ${ }^{22}$ And also as the high acidic, $\mathrm{V}_{2} \mathrm{O}_{5}$ then dissolved according to Equation (4). The reaction showed in Equation (3) and (4) occurred alternately in the anolyte. The competition between the generation and dissolution of $\mathrm{V}_{2} \mathrm{O}_{5}$ resulting the electrochemical oscillation. ${ }^{23}$ The $\mathrm{H}^{+}$in the anolyte would migrate to the cathode through the Nafion membrane. As the reaction happened like Equation (2), the $\mathrm{H}^{+}$in the system was decreased, the solubility of $\mathrm{V}(\mathrm{V})$ increased $^{21}$ and reactions showed in Equations (3) and (4) was interrupted, and then the electrochemical oscillation was disappeared. The reaction could be expressed like in Figure 4.

$$
\begin{aligned}
& 2 \mathrm{VO}_{2}^{+}+\mathrm{H}_{2} \mathrm{O} \rightarrow \mathrm{V}_{2} \mathrm{O}_{5}+2 \mathrm{H}^{+} \\
& \mathrm{V}_{2} \mathrm{O}_{5}+\mathrm{H}^{+} \rightarrow 2 \mathrm{VO}_{2}++\mathrm{H}_{2} \mathrm{O}
\end{aligned}
$$

The electrochemical oscillation was an interesting self-organizing phenomenon in which the current or potential periodically fluctuates at a constant external electric field. ${ }^{24,25}$ It was also a typical chaotic phenomenon with non-linear and non-equilibrium. The main parameters to characterize chaotic phenomenon include Lyapunov exponent, correlation dimension and Kolmogorov entropy etc. ${ }^{26}$
Lyaponov exponent denotes the convergent or divergent average exponential rate of the adjacent orbits in the phase space of the system, and the value of the largest Lyapunov exponent (LLE) also apply to judge whether a nonlinear time's series is in chaos or not. ${ }^{26-28}$ The LLE of the potential-time series was calculated using Wolf algorithm and the results were shown in Figure 5.

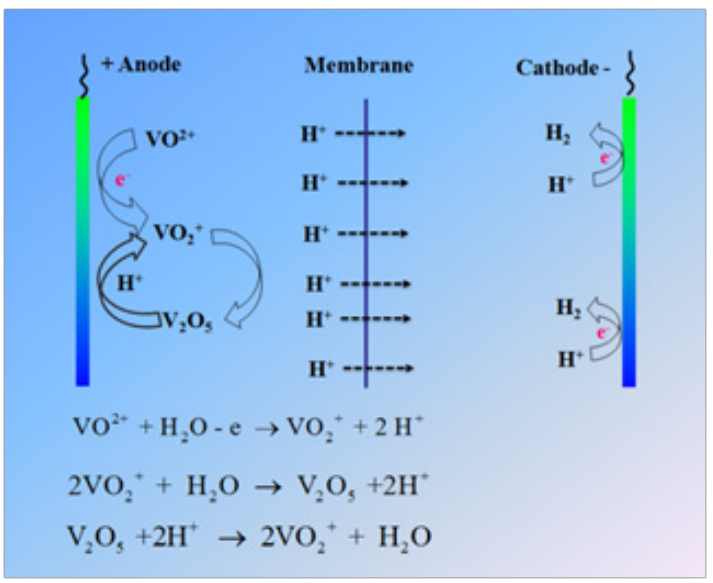

Figure 4 The reaction model in the charging process.

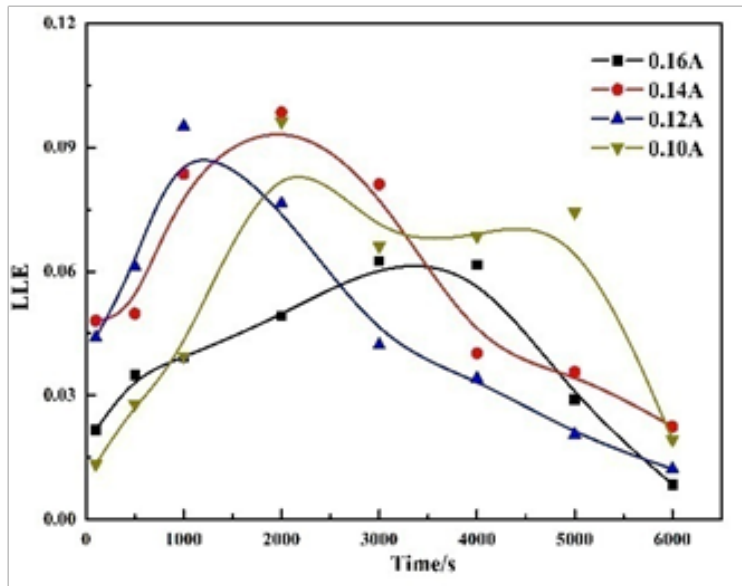

Figure $\mathbf{5}$ The dependence of LLE on the time in different charging current.

Figure 5 indicated that the LLE was positive for all experiments, which was consistent with the results that the electrochemical oscillation was a typical chaotic phenomenon. The LLE initially increased and then decreased with the electrochemical oscillation emitted. And it could be inferred that LLE would be decreased to below zero when the electrochemical oscillation disappeared from Figure 5 .

In summary, the electrochemical oscillation was first observed during the charging process of anolyte in vanadium redox flow battery. It could be explained in term of the competition between the growth and the chemical dissolution of $\mathrm{V}_{2} \mathrm{O}_{5}$ film around the anode in the $\mathrm{H}_{2} \mathrm{SO}_{4}$ solution. The controlling and usage of the chaotic phenomenon was beneficial for improving the charge efficiency and energy-saving as the oscillation regular extra power consumption.

\section{Acknowledgements}

This work was supported by the Nation 973 projects of China (No. MOST2011CB933300) the Natural Science Foundation of China (No. 
51274261) and the program for Chongqing University Postgraduates' Innovation Project (CYB15045).

\section{Conflict of interest}

The authors declare no conflict of interest.

\section{References}

1. RR Moskalyk, AM Alfantazi. Processing of vanadium:a review. Minerals Engineering. 2003;16(9):793-805.

2. H Peng, Z Liu, C Tao. Leaching Kinetics of Vanadium with Electrooxidation and $\mathrm{H}_{2} \mathrm{O}_{2}$ in Alkaline Medium. Energy \& Fuels. 2016;30:78027807.

3. H Peng, Z Liu, C Tao. Selective leaching of vanadium from chromium residue intensified by electric field. Journal of Environmental Chemical Engineering. 2015;3(2):1252-1257.

4. Y Dong, KY Zhou, Y Lu, et al. Effect of vanadium addition on the microstructure and properties of $\mathrm{AlCoCrFeNi}$ high entropy alloy. Materials \& Design. 2014;57:67-72.

5. JA Valverde, A Echavarria, JG Eon, et al. $\mathrm{V}-\mathrm{Mg}-\mathrm{Al}$ catalyst from hydrotalcite for the oxidative dehydrogenation of propane. Reaction Kinetics Mechanisms and Catalysis. 2014;111(2):679-696.

6. SY Lu, QL Wang, WR Stevens, et al. Study on the decomposition of trace benzene over $\mathrm{V}_{2} \mathrm{O}_{5}-\mathrm{WO}_{3} / \mathrm{TiO}_{2}$-based catalysts in simulated flue gas. Applied Catalysis B-Environmental. 2014;147:322-329.

7. NJ Nicholas, G da Silva, S Kentish, et al. Use of Vanadium(V) Oxide as a Catalyst for $\mathrm{CO}_{2}$ Hydration in Potassium Carbonate Systems. Industrial \& Engineering Chemistry Research. 2014;53(8):3029-3039.

8. W Wang, B Jiang, LW $\mathrm{Hu}$, et al. Single crystalline $\mathrm{VO}_{2}$ nanosheets:A cathode material for sodium-ion batteries with high rate cycling performance. Journal of Power Sources. 2014;250:181-187.

9. C Ding, H Zhang, X Li, et al. Vanadium Flow Battery for Energy Storage:Prospects and Challenges. Journal of Physical Chemistry Letters. 2013;4(8):1281-1294.

10. BY Xiong, JY Zhao, KJ Tseng, et al. Thermal hydraulic behavior and efficiency analysis of an all-vanadium redox flow battery. Journal of Power Sources. 2013;242:314-324.

11. E Sum, M Rychcik, M Skyllas Kazacos. Investigation of the V(V)/V(IV) system for use in the positive half-cell of a redox battery. Journal of Power Sources. 1985;16(2):85-95.

12. V Viswanathan, A Crawford, D Stephenson, et al. Cost and performance model for redox flow batteries. Journal of Power Sources. 2014;247:1040-1051.
13. S Rudolph, U Schroder, IM Bayanov, et al. Corrosion prevention of graphite collector in vanadium redox flow battery. Journal of Electroanalytical Chemistry. 2013;709:93-98.

14. P Trogadas, OO Taiwo, B Tjaden, et al. X-ray micro-tomography as a diagnostic tool for the electrode degradation in vanadium redox flow batteries. Electrochemistry Communications. 2014;48:155-159.

15. $\mathrm{XX} \mathrm{Wu}, \mathrm{HF} \mathrm{Xu}, \mathrm{L} \mathrm{Lu}$, et al. $\mathrm{PbO}_{2}$-modified graphite felt as the positive electrode for an all-vanadium redox flow battery. Journal of Power Sources. 2014;250:274-278.

16. JKim, JD Jeon, SY Kwak. Nafion-based composite membrane with a permselective layered silicate layer for vanadium redox flow battery. Electrochemistry Communications. 2014;38:68-70.

17. D Chen, MA Hickner, E Agar, et al. Selective anion exchange membranes for high coulombic efficiency vanadium redox flow batteries. Electrochemistry Communications. 2013;26:37-40.

18. R Ogawa, H Matsushima, M Ueda. Hydrogen isotope separation with an alkaline membrane fuel cell. Electrochemistry Communications. 2016;70:5-7.

19. JC Li, YP Zhang, L Wang. Preparation and characterization of sulfonated polyimide $/ \mathrm{TiO}_{2}$ composite membrane for vanadium redox flow battery. Journal of Solid State Electrochemistry. 2014;18(3):729-737.

20. X Zhou, C Wei, M Li, et al. Thermodynamics of vanadium-sulfur-water systems at 298 K. Hydrometallurgy. 2011;106(1-2):104-112.

21. S Banwen, L Yuji. Inorganic Chemistry Series. China: Science press; 1998.

22. CF Baes, RE Mesmer. The Hydrolysis of Cations. USA: John Wiely; 1976.

23. V Alonzo, A Darchen, E Le Fur, et al. Electrosynthesis of vanadophosphate by anodic oxidation of vanadium in phosphoric acid solutions. Electrochemistry Communications. 2002;4(11):877-880.

24. X Fan, J Hou, D Sun, et al. Mn-oxides catalyzed periodic current oscillation on the anode. Electrochimica Acta. 2013;102:466-471.

25. X Fan, D Yang, L Ding, et al. Periodic Current Oscillation Catalyzed by $\boldsymbol{\delta}-\mathrm{MnO}_{2}$ Nanosheets. Chemphyschem. 2015;16(1):176-180.

26. K Deng, J Li, S Yu. Optik. International Journal for Light and Electron Optics. 2014;125(13):3071-3075.

27. H Hu, D Liu. The Judgment of Chaotic Detection System's State Based on the Lyapunov Exponent. Procedia Engineering. 2012;29:2894-2898.

28. Z Liu, X Zheng, D Liu, et al. Enhancement of liquid-liquid mixing in a mixer-settler by a double rigid-flexible combination impeller. Chemical Engineering and Processing: Process Intensification. 2014;86:69-77. 